\title{
Article
}

\section{Cutting force when machining hardened steels}

\author{
Karel Osička ${ }^{1 *}$, Josef Chladil ${ }^{1}$, Petra Sliwková ${ }^{1}$ and Jan Zouhar ${ }^{1}$ \\ 1 Brno University of Technology, Faculty of Mechanical Eengineering, Technická 2996/2, 61602 Brno, Česká \\ republika; osicka@fme.vutbr.cz; chladil@fme.vutbr.cz; sliwkova@fme.vutbr.cz; zouhar@ fme.vutbr.cz \\ * Correspondence: osicka@fme.vutbr.cz
}

\begin{abstract}
This article deals primarily with the problem of determining the cutting force when machining hardened steels. Secondary issues are focused on the evaluation of surface quality on machined samples and the recommendation of cutting conditions. A wide variety of components are used in engineering, the final heat treatment of which is hardening. These components are usually critical in a particular product. The quality of these components determines the correct functioning of the entire technical equipment and ultimately its service life. In our case, these are the core parts of thrust bearings, specifically the rolling elements. The subject of the experiment is machining these components in the hardened state with cubic boron nitride tools and continuous measurement of the cutting force using a dynamometer. The following evaluation assesses the surface quality by both touch and non-touch methods. A structural equation with appropriate constant and exponents was then constructed from the data obtained using the dynamometer.
\end{abstract}

Keywords: hardened steel; cubic boron nitride; rolling body; structural equations

\section{Introduction}

The basic balance sheet builds on the results achieved during participation in projects where machining of hardened steels was the subject of research at the Department of Machining at the Faculty of Mechanical Engineering of Brno University of Technology. In these projects, the subject of the research was the search for optimal cutting conditions, as well as the search for the relationship between tool unloading and process stability of this machining method. The results can be found in the following published articles "Machining of hardened bearing steels"[1]," Contribution to turning hardened steel" [2]," Influence of cutting tool overhangs at machining of hardened steels" [3]," High- speed cutting of bearing rings from material 100Cr6" [4]," Analysis of selected aspects of turned bearing rings regarding required work piece quality" [5], "Tension of the surface layer in machining hardened steels" [6] and Hardened steels and their machining [7].

So far, application research of this technology has been primarily focused on machining of functional surfaces of body and shaft rings. This paper is mainly concerned with machining of rolling bodies in the hardened state, real-time measurement of the cutting force during machining and determination of the structural equation from the obtained values. These data are not widely available in the literature and have limited validity for specific cutting conditions [8]. Surface roughness parameters after finishing machining are given as a secondary output.

\section{Materials and Methods}

The experiment is focused at measuring the cutting forces when machining the functional surface of the component "Rolling Body", which is the outer diameter. The implemented manufacturing process includes:

- Machining of hardened components by finishing technology with a CBN tool;

- Carrying out an experiment to measure the cutting forces;

- Evaluation of the force analysis;

- Development of a structural equation; 
- Evaluation of the surface quality of the functional surface by the touch method;

- Evaluation of the surface quality of the functional surface by non-contact method.

The experiments were carried out according to the available machinery and laboratory equipment at the Faculty of Mechanical Engineering of Brno University of Technology on the following equipment:

- Universal lathe SV 18 RD;

- Dynamometer Kistler 9257B;

- $\quad$ Taylor Hobson Surtronic S 100 roughness gauge;

- $\quad$ Alicona Infinite Focus G5 non-contact instrument.

Component material the rolling element is $100 \mathrm{Cr} 6$ according to ISO. The material composition is in the Table 1. The hardness of the samples is 64-62 HRC.

Table 1. Material composition $100 \mathrm{Cr} 6(\%)$

\begin{tabular}{cccccccc}
\hline Steel & C & Si & Mn & Cr & Mo & P & S \\
\hline 100 Cr6 & $0.93-1.05$ & $0.15-0.35$ & $0.25-0.45$ & $1.35-1.60$ & max.0.1 & 0.025 & 0.015 \\
\hline
\end{tabular}

\subsection{Implementation of the cutting force measurement experiment}

The experiment was carried out on 12 samples of rolling elements for larger bearing types.

The approximate dimensions of the sample shown in Figure 1:

- $\quad 32$;

- $\quad$ Length $(\mathrm{mm})$

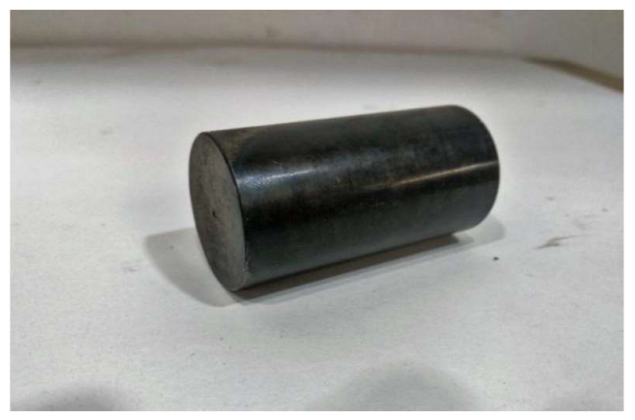

Figure 1 Sample of a semi-finished rolling element.

Unlike previous experiments with bearing rings, the SP280 SY machine was not used because of the practically impossible placement of the Kistler measuring system on this machine, namely the placement of the measuring probes on the vertical slide of the machine. In previous experiments [2] cutting tools from SECO were used but in this experiment alternative tools from Dormer Pramet were applied.

\subsection{Technological conditions of machining when measuring with a Kistler dynamometer}

The machine used for the experiment was the SV $18 \mathrm{RD}$, which is a lathe that has been verified for rigidity. The machine also has a considerable range of cutting speeds that can be continuously controlled. The main advantage of this conventional lathe is the possibility of placing the measuring probes of the Kistler dynamometer also on the back of the slide.

The specific tools used by Dormer Pramet were as follows:

- $\quad$ Tool holder PCLNL 2525 M 12 in left-hand version;

- $\quad$ Replaceable insert CNGA 120408 S 01020B shown in Figure 2, made of TB310, polycrystalline cubic boron nitride, suitable for use without cutting fluid. 


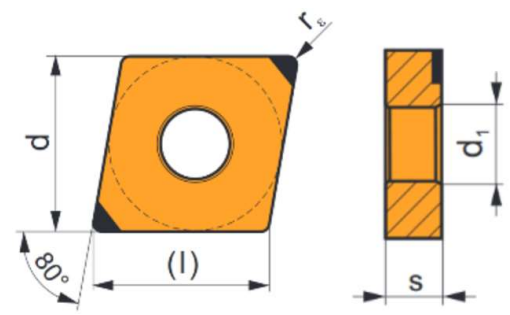

Figure 2 General dimensions of the insert.

Table 2 Dimensional specification of the insert used.

\begin{tabular}{|c|c|c|c|c|c|c|c|}
\hline $\begin{array}{c}\mathbf{r}_{\varepsilon} \\
(\mathrm{mm})\end{array}$ & $\begin{array}{c}a_{p} \\
(\mathrm{~mm})\end{array}$ & $\begin{array}{c}f \\
(\mathrm{~mm})\end{array}$ & $\begin{array}{c}\mathrm{vc}_{\mathrm{c}} \\
\left(\mathrm{m} \cdot \mathrm{min}^{-1}\right)\end{array}$ & $\begin{array}{c}\mathrm{d} \\
(\mathrm{mm})\end{array}$ & $\begin{array}{c}\mathrm{d}_{1} \\
(\mathrm{~mm})\end{array}$ & $\begin{array}{c}1 \\
(\mathrm{~mm})\end{array}$ & $\begin{array}{c}\mathrm{s} \\
(\mathrm{mm})\end{array}$ \\
\hline 0.8 & $0.1-2.7$ & $0.02-0.20$ & $100-200$ & 12.7 & 5.16 & 12.9 & 4.76 \\
\hline
\end{tabular}

The complete tool holder including the inserts used during the experiment placed on the probe of the Kistler 9257B dynamometer is shown in Figure 3.

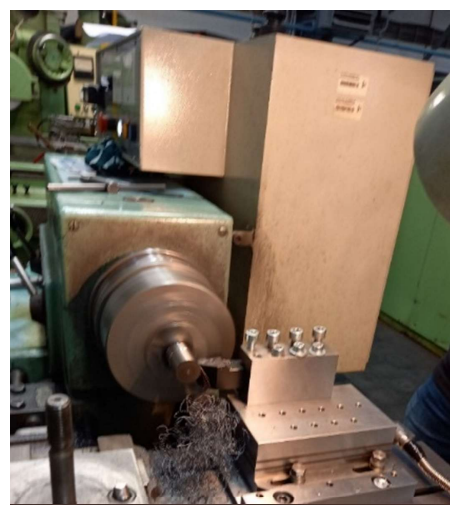

Figure 3 The complete instrument used during the experiment.

Table 3 Cutting conditions of the experiment.

\begin{tabular}{cccc}
\hline $\begin{array}{c}\text { Sample } \\
\text { No. }\end{array}$ & $\begin{array}{c}\mathbf{v}_{\mathbf{c}} \\
\left(\mathbf{m} \cdot \mathbf{m i n}^{-1}\right)\end{array}$ & $\begin{array}{c}\mathbf{f} \\
(\mathbf{m m})\end{array}$ & $\begin{array}{c}\mathbf{a}_{\mathbf{p}} \\
(\mathbf{m m})\end{array}$ \\
\hline 1 & & 0.05 & 0.2 \\
2 & & 0.05 & 0.35 \\
3 & 130 & 0.1 & 0.2 \\
4 & & 0.1 & 0.35 \\
\hline 5 & & 0.05 & 0.2 \\
6 & \multirow{2}{*}{155} & 0.05 & 0.35 \\
7 & & 0.1 & 0.2 \\
8 & & 0.1 & 0.35 \\
\hline 9 & & 0.05 & 0.2 \\
10 & & 0.05 & 0.35 \\
11 & 180 & 0.1 & 0.2 \\
12 & & 0.1 & 0.35 \\
\hline
\end{tabular}

The cutting conditions for machining were chosen according to the experience from previous experiments [1], [2], [3], but in a wider range, so that the mathematical dependencies could be subsequently determined. The specific values of the cutting 
conditions are given in Table 3. These are always four combinations of feed rate $f$ and blade cutting width $a_{p}$ at three different cutting speeds vc. Sample 1 after machining is shown in Figure 4.

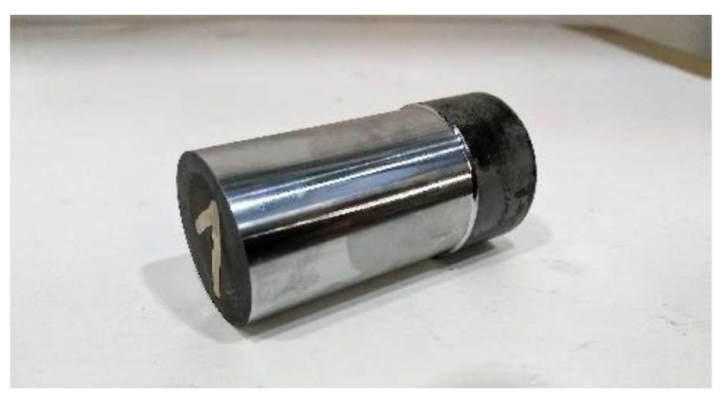

Figure 4 Sample 1 after machining.

The machining was carried out without process fluid and due to the geometry of the cutting insert (without chip sealer) a continuous segmented chip is realized, as shown in Figure 3.

\subsection{Measurement of cutting forces with a Kistler dynamometer}

A Kistler 9257B stationary dynamometer was used to evaluate the cutting force measurements. During longitudinal turning, the force components are measured in three directions according to the coordinate system, i.e. in the $\mathrm{x}, \mathrm{y}$ and $\mathrm{z}$ axes, corresponding to the force components $F_{x}, F_{y}$ and $F_{z}$. The measuring apparatus consists of a dynamometer, a Kistler 5070A hub amplifier and a data acquisition and analysis system by means of which the data are transferred to a computer. A realistic connection of the control and evaluation part of the assembly is shown in Figure 5.

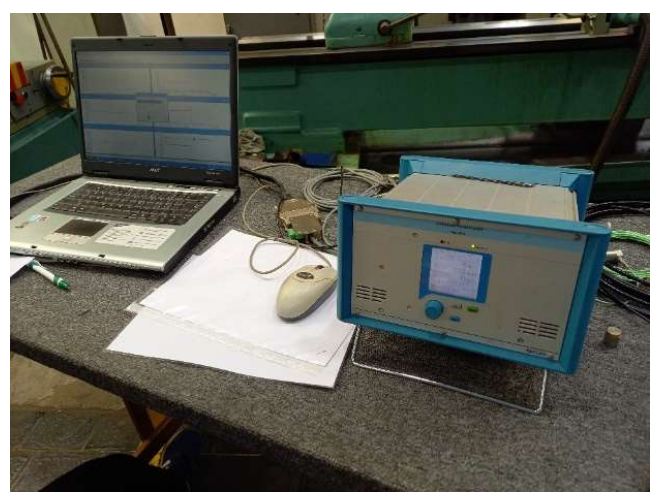

Figure 5 Real connection of a part of the assembly.

As each sub-sample was machined, a measurement was run and after turning was completed, the values were recorded and stored in DynoWare. The measurement was set to 60 seconds to cover all the machine times when machining each sample. Unwanted extreme measurement dates were filtered out.

2.4 Surface quality measurement by the touch method

Measurements of individual surface roughness parameters were made with a Taylor Hobson Surtronic S-128 roughness tester, shown in Figure 6. 


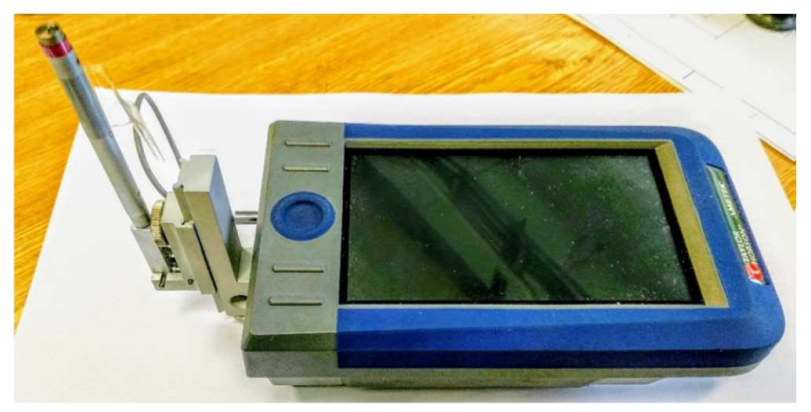

Figure 6 The Taylor Hobson Surtronic S-128 roughness tester used.

The technical parameters of the roughness tester are as follows:

- Instrument weight $(\mathrm{kg})$

0.5 ;

- $\quad$ Operating conditions - temperature $\left({ }^{\circ} \mathrm{C}\right)$

5 to 40 ;

- Sensor type

- $\quad$ Pressure force $(\mathrm{mg})$

Inductive;

- $\quad$ Sensor range $(\mu \mathrm{m})$

150 - 300;

- $\quad$ Sensor resolution $(\mathrm{nm})$

400 / 100 / 10;

- $\quad$ Evaluated length (mm)

- Maximum X-axis range ( $\mathrm{mm})$

$50 / 10 / 5$

$0.25-25$;

25.5;

- $\quad$ Calibration - Roughness standard - according to ISO 4287.

\subsection{Surface quality measurement by non-contact method}

The evaluation of the surface quality of the functional area by the non-contact method was performed on the Alicona Infinite Focus G5 (hereafter referred to as Alicona) and is shown in Figure 7.

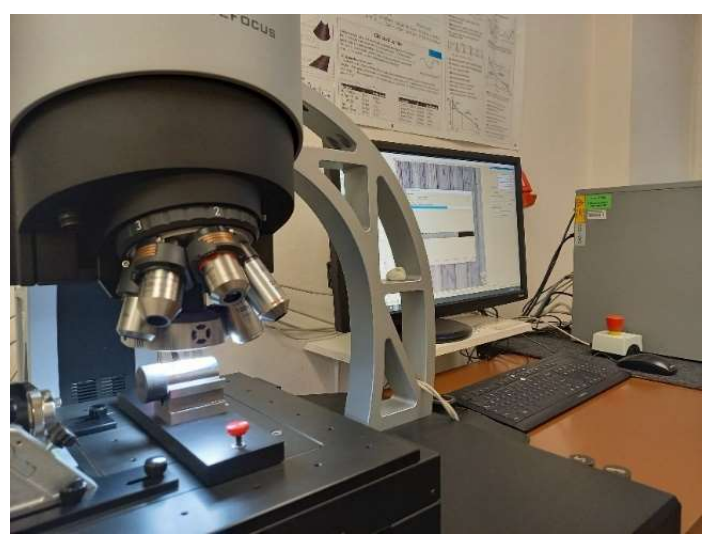

Figure 7 Measurements on the Alicona instrument.

The main disadvantage is the problem with the reflectivity of some surfaces, which means that more lenses and measuring conditions have to be tried [9], [10].

The measurements were carried out under the following conditions:

- $\quad$ used 50x lens;

- $\quad$ filter $\operatorname{Lc}[\mu \mathrm{m}]$

- $\quad$ profile measurement path length [mm] 4.

\section{Results}

The results include the issue of cutting forces and the evaluation of surface integrity by both touch and non-touch methods. Due to the large amount of data, the graphical representation is limited to selected samples of components, namely parts 5, 6, 8 and 12 . 
The measurement data were converted to a .txt file and then graphical dependencies of the time course on the force load were created in Microsoft Excel. Due to the very small scatter of individual force values in virtually all graphs, these are sufficient as input data for the structural equation. The average values of the individual cutting forces at the specified cutting conditions are given in Table 4.

Table 4 Average values of individual cutting forces

\begin{tabular}{|c|c|c|c|c|c|c|c|}
\hline $\begin{array}{c}\text { Sample } \\
\text { No. }\end{array}$ & $\begin{array}{c}\mathrm{Vc} \\
\left(\mathrm{m} \cdot \mathrm{min}^{-1}\right)\end{array}$ & $\begin{array}{c}f \\
(\mathrm{~mm})\end{array}$ & $\begin{array}{c}a_{p} \\
(\mathrm{~mm})\end{array}$ & $\begin{array}{c}\text { Force } F_{c} \\
(\mathrm{~N})\end{array}$ & $\begin{array}{c}\text { Force } F_{f} \\
(\mathbf{N})\end{array}$ & $\begin{array}{c}\text { Force } F_{p} \\
\text { (N) }\end{array}$ & $\begin{array}{c}\text { Resulting } \\
\text { force F } \\
\text { (N) }\end{array}$ \\
\hline 1 & \multirow{4}{*}{130} & 0.05 & 0.2 & 121.4 & 49.0 & 71.0 & 148.9 \\
\hline 2 & & 0.05 & 0.35 & 165.6 & 99.7 & 114.1 & 224.5 \\
\hline 3 & & 0.1 & 0.2 & 167.9 & 64.8 & 112.8 & 212.4 \\
\hline 4 & & 0.1 & 0.35 & 224.9 & 117.4 & 175.5 & 308.5 \\
\hline 5 & \multirow{4}{*}{155} & 0.05 & 0.2 & 133.6 & 54.8 & 72.3 & 161.5 \\
\hline 6 & & 0.05 & 0.35 & 153.9 & 106.6 & 115.3 & 219.9 \\
\hline 7 & & 0.1 & 0.2 & 171.7 & 59.5 & 97.3 & 206.2 \\
\hline 8 & & 0.1 & 0.35 & 206.1 & 128.3 & 175.5 & 299.6 \\
\hline 9 & \multirow{4}{*}{180} & 0.05 & 0.2 & 119.0 & 47.1 & 68.7 & 145.3 \\
\hline 10 & & 0.05 & 0.35 & 147.5 & 87.7 & 103.3 & 199.0 \\
\hline 11 & & 0.1 & 0.2 & 152.1 & 62.2 & 123.2 & 205.5 \\
\hline 12 & & 0.1 & 0.35 & 199.1 & 118.6 & 197.4 & 304.5 \\
\hline
\end{tabular}

Figures 8 to 11 show the force load time histories for the selected samples, including the calculated total cutting force F. For all machined samples, one pass and one measurement was performed on each sample.

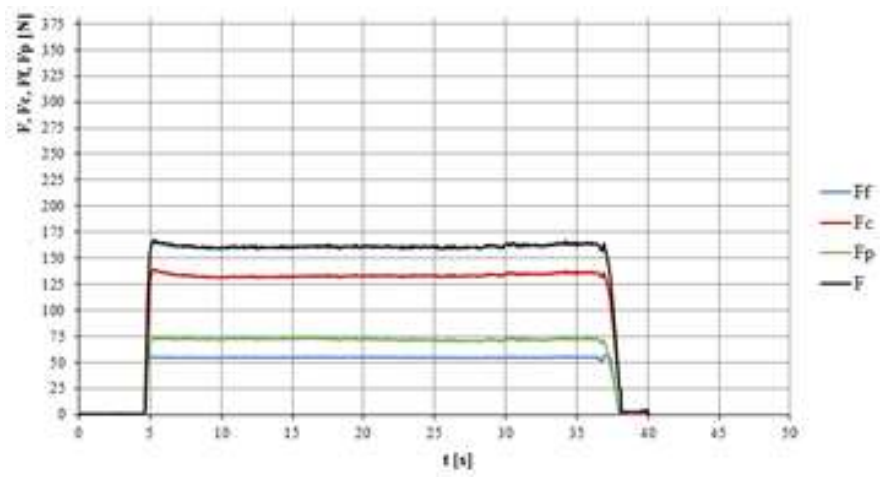

Figure 8 Force load history of sample $5\left(v_{c}=155 \mathrm{~m} \cdot \mathrm{min}^{-1}, \mathrm{f}=0.05 \mathrm{~mm}, \mathrm{ap}_{\mathrm{p}}=0.2 \mathrm{~mm}\right)$.

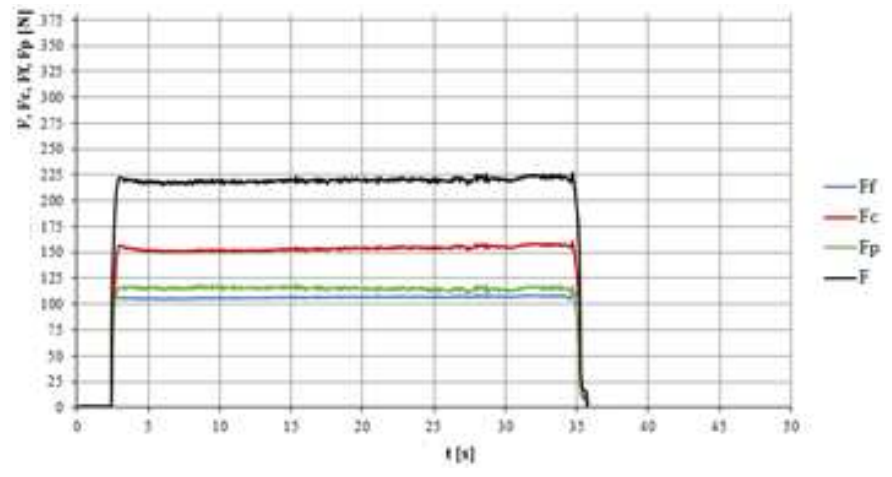


Figure 9 Force load history of sample $6\left(v_{c}=155 \mathrm{~m} \cdot \mathrm{min}^{-1}, \mathrm{f}=0.05 \mathrm{~mm}, \mathrm{ap}_{\mathrm{p}}=0.35 \mathrm{~mm}\right)$.

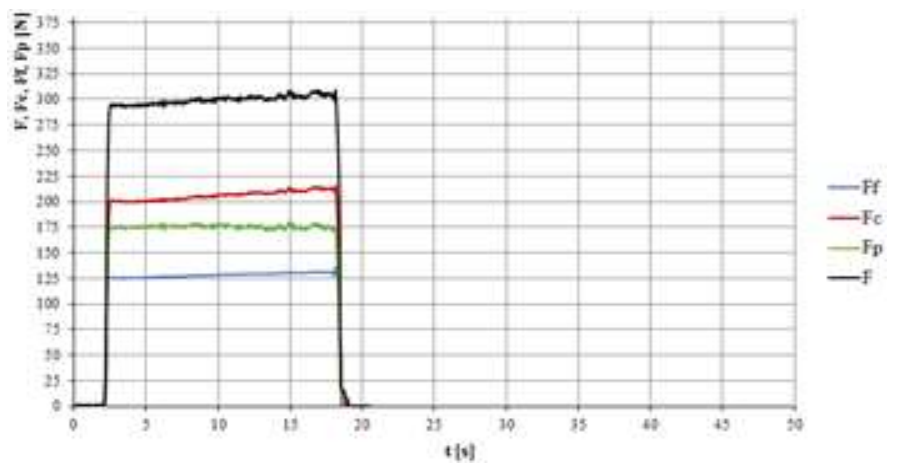

Figure 10 Force load history of sample $8\left(v_{c}=155 \mathrm{~m} \cdot \mathrm{min}^{-1}, \mathrm{f}=0.1 \mathrm{~mm}, \mathrm{ap}_{\mathrm{p}}=0.35 \mathrm{~mm}\right)$.

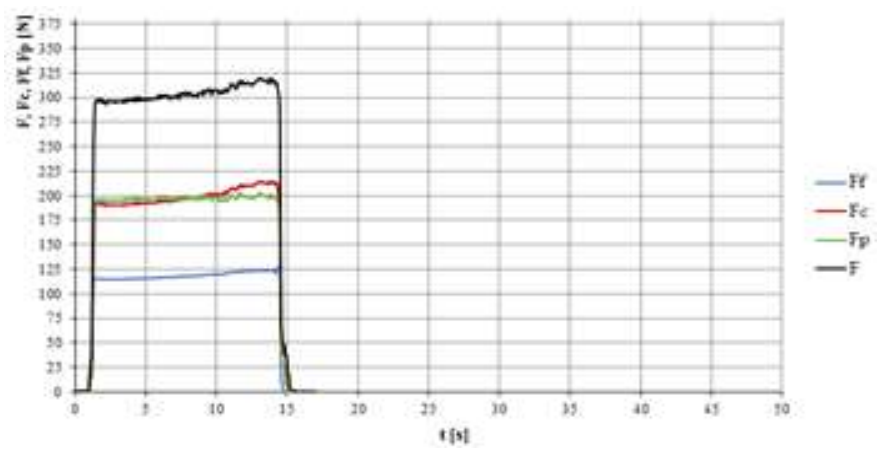

Figure 11 Force load history of sample $10\left(v_{c}=180 \mathrm{~m} \cdot \mathrm{min}^{-1}, \mathrm{f}=0.1 \mathrm{~mm}, \mathrm{ap}_{\mathrm{p}}=0.35 \mathrm{~mm}\right)$.

\subsection{Derivation of the structural equation}

The derivation of the structural equation for the cutting force $\mathrm{F}_{\mathrm{c}}$ for turning material in the hardened state is based on the data in Table 4 and is based on the following equation 3.1:

$$
F_{C}=C_{F_{C}} \cdot a_{p}^{x_{F_{C}}} \cdot f^{y_{F_{C}}} \cdot v_{c}^{z_{F_{C}}}
$$

This relationship is empirical and depends on the constant $\mathrm{C}_{\mathrm{Fc}}$, the exponents $\mathrm{XFc}_{\mathrm{c}}, \mathrm{yFc}_{\mathrm{Fc}}$ and $\mathrm{ZFc}_{\mathrm{c}}$ and the variables in this case the blade width $\mathrm{ap}_{\mathrm{p}}$, the feed $\mathrm{f}$ and possibly the cutting speed Vc. The values of the constant $\mathrm{CF}_{\mathrm{Fc}}$. and the exponents $\mathrm{XFc}_{\mathrm{F}}, \mathrm{yF}_{\mathrm{F}}$ and $\mathrm{ZFF}_{\mathrm{F}}$ depend on the specific machining conditions and are valid within a certain range. Furthermore, the type of material and its condition have an influence, which can be expressed by the machinability class. When calculating the cutting force according to this equation, we have to take into account an inaccuracy which will be proportional to the difference between our machining conditions and those used to calculate the constant $\mathrm{C}_{\mathrm{Fc}}$ and the exponents $\mathrm{XFc}_{\mathrm{Fc}} \mathrm{yFc}_{\mathrm{F}}$ and $\mathrm{ZFc}$.

The methodology for determining the specific form of the structural equation requires the following simplification. As can be seen in Table 4, the influence of the cutting speed is minimal, which implies the assumption of a very small value of the exponent $\mathrm{ZFc}$. of about \pm 0.05 . The cutting speed term in the general formula is therefore not included and its possible influence is reflected in the value of the constant $C_{\text {Fc. From }}$ Table 4, the individual values of $F_{c}$ are averaged for the combinations of feed $f$ and cutting edge width ap used and listed in Table 5 for use in the following calculation.

$$
F_{C}=C_{F_{C}} \cdot a_{p}^{x_{F_{C}}} \cdot f^{y_{F_{C}}} \Rightarrow C_{F_{C}}=\frac{F_{C}}{a_{p}^{x_{F_{C}}} \cdot f^{y_{F_{C}}}}
$$


Equation 3.2 in its modified form is the basic formula for determining the methodology for determining the values of the exponents $\mathrm{XFc}_{\mathrm{Fc}} \mathrm{yFc}_{\mathrm{Fc}}$ and subsequently the constant $\mathrm{C}_{\mathrm{Fc}}$.

Table 5 Averaged values of cutting force $F_{c}$ for combinations of feed $f$ and cutting edge width ap

\begin{tabular}{cccc}
\hline $\begin{array}{c}\text { Combination } \\
\mathbf{f} \text { and } \mathbf{a p}_{\mathbf{p}}\end{array}$ & $\begin{array}{c}\mathbf{f} \\
\mathbf{( m m )}\end{array}$ & $\begin{array}{c}\mathbf{a p}_{\mathbf{p}} \\
\mathbf{( \mathbf { m m } )}\end{array}$ & $\begin{array}{c}\mathbf{F}_{\mathbf{c}} \\
\mathbf{( N )}\end{array}$ \\
\hline 1 & 0.05 & 0.2 & 124.7 \\
2 & 0.05 & 0.35 & 155.6 \\
3 & 0.1 & 0.2 & 163.9 \\
4 & 0.1 & 0.35 & 210.3 \\
\hline
\end{tabular}

\subsubsection{Derivation of the exponent $\mathrm{XF}_{\mathrm{F}}$}

To derive the exponent $\mathrm{XFc}_{\mathrm{c}}$, a constant displacement value $\mathrm{f}$ is assumed and the equation takes the following form 3.3.

$$
F_{C}=C_{F_{a_{p}}} \cdot a_{p}^{x_{F_{C}}}
$$

After logarithmization, $\mathrm{XFC}_{\mathrm{F}}$ can be defined as the directive of the line $\operatorname{tg} \alpha$.

$$
\log F_{C}=\log C_{F_{a_{p}}}+x_{F_{C}} \log a_{p}
$$

A graphical representation is shown in Figure 12.

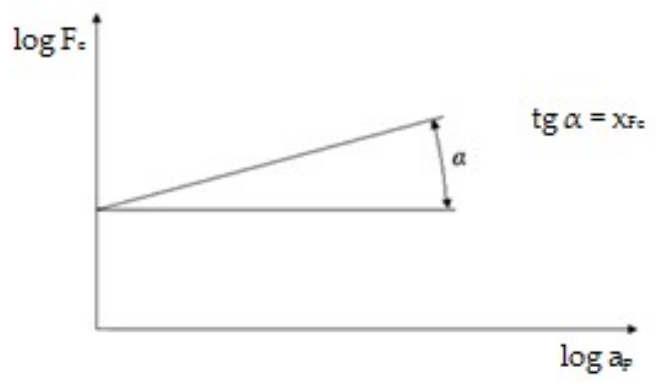

Figure 12 Graphical representation of $\mathrm{XFc}$.

Equation 3.5 to calculate $\mathrm{XFc}_{\mathrm{f}}$ from the data in Table 5:

$$
x_{F_{C}}=\operatorname{tg} \alpha=\frac{\log F_{C 2}-\log F_{C 1}}{\log a_{p 2}-\log a_{p 1}}
$$

After setting the values of the combination of cutting conditions for a constant feed $\mathrm{f}$ $0.1 \mathrm{~mm}$.

$$
x_{F_{C}}=\operatorname{tg} \alpha=\frac{\log 210.3-\log 163.9}{\log 0.35-\log 0.2}=0.444
$$

3.2.2 Derivation of the exponent yfc

To derive the exponent $\mathrm{yFc}_{\mathrm{f}}$ a constant value of the cutting edge width ap is assumed and the equation takes the following form 3.7.

$$
F_{C}=C_{F_{f}} \cdot f^{y_{F_{C}}}
$$


After logarithmization, $\mathrm{yFc}_{\mathrm{c}}$ can be defined as the directive of the line $\operatorname{tg} \alpha$.

$$
\log F_{C}=\log C_{F_{f}}+y_{F_{C}} \log f
$$

A graphical representation is shown in Figure 13.

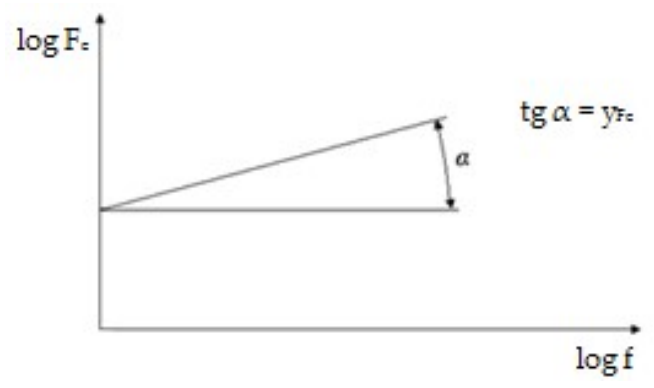

Figure 13 Graphical representation of yfc.

Equation 3.9 to calculate $\mathrm{yFc}_{\mathrm{c}}$ from the data in Table 5:

$$
y_{F_{C}}=\operatorname{tg} \alpha=\frac{\log F_{C 2}-\log F_{C 1}}{\log f_{2}-\log a_{1}}
$$

After setting the values of the combination of cutting conditions for a constant cutting edge width ap $0.35 \mathrm{~mm}$.

$$
y_{F_{C}}=\operatorname{tg} \alpha=\frac{\log 210.3-\log 155.6}{\log 0.1-\log 0.05}=0.437
$$

\subsubsection{Determination of the constant $\mathrm{C}_{\mathrm{Fc}}$}

Given the already calculated values of the exponents $\mathrm{xFc}_{\mathrm{Fc}}$ and $\mathrm{yFc}_{\mathrm{c}}$, the constant $\mathrm{C}_{\mathrm{Fc}} \mathrm{can}$ be determined using equation 3.2 by substituting one of the combinations of the blade width $a_{p}$, the feed rate $f$ and the corresponding averaged value of the measured cutting force $F_{c}$ from Table 5 .

$$
C_{F_{C}}=\frac{210.3}{0.35^{0.444} \cdot 0.1^{0.437}}=918.34
$$

\subsubsection{Final form of the structural equation}

The final form of the structural equation for the calculation of $\mathrm{F}_{\mathrm{c}}$ after adding the rounded numerical values of the constant $\mathrm{CFc}_{\mathrm{Fc}}$, and the exponents $\mathrm{XFc}_{\mathrm{F}}, \mathrm{yFc}_{\mathrm{c}}$ is given in relation 3.12 .

$$
F_{C}=918 \cdot a_{p}^{0.44} \cdot f^{0.44}[N]
$$

Given virtually the same value of the exponents $\mathrm{XFc}_{\mathrm{F}}, \mathrm{yFc}_{\mathrm{c}}$, the structural equation can be written in the simplified form 3.13.

$$
F_{C}=918 \cdot\left(a_{p} \cdot f\right)^{0.44}[N]
$$

This form of the structural equation holds for the range of cutting conditions corresponding to the experiment. This range can be extended in the following range, namely:

- Material 10 Cr6 in hardened condition (HRC) 64-62;

- Cutting edge width $\mathrm{ap}_{\mathrm{p}}(\mathrm{mm}) \quad 0.1-0.45$;

- $\quad$ Feed f (mm) 0.05-0.15;

- Cutting speed vc (m.min-1) 110-200. 
The evaluation of the quality of the functional area was carried out preferentially by the touch method and for the verification of the measured data the measurement was carried out by the non-contact method.

3.3.1 Evaluation of the surface quality of the functional area by the touch method

The measurements of individual surface roughness parameters were performed with a Taylor Hobson Surtronic S-128 roughness tester. Each measurement was performed 3 times and Table 6 shows the averaged values of selected surface quality parameters according to ISO 4287.

Table 6 Values of selected surface quality parameters obtained under the specified cutting conditions

\begin{tabular}{ccccccc}
\hline $\begin{array}{c}\text { Sample } \\
\text { No. }\end{array}$ & $\begin{array}{c}\mathbf{v}_{\mathbf{c}} \\
\left(\mathbf{m}_{\mathbf{m i n}} \mathbf{- 1}\right)\end{array}$ & $\begin{array}{c}\mathbf{f} \\
(\mathbf{m m})\end{array}$ & $\begin{array}{c}\mathbf{a} \mathbf{p} \\
(\mathbf{m m})\end{array}$ & $\begin{array}{c}\mathbf{R a} \\
(\boldsymbol{\mu m})\end{array}$ & $\begin{array}{c}\mathbf{R z} \\
(\boldsymbol{\mu m})\end{array}$ & $\begin{array}{c}\mathbf{R m r} \\
(\mathbf{\%})\end{array}$ \\
\hline 1 & & 0.05 & 0.2 & 0.38 & 2.27 & 48.9 \\
2 & \multirow{2}{*}{130} & 0.05 & 0.35 & 0.34 & 2.17 & 48.7 \\
3 & & 0.1 & 0.2 & 0.36 & 2.17 & 46.7 \\
4 & & 0.1 & 0.35 & 0.37 & 2.23 & 47.7 \\
\hline 5 & & 0.05 & 0.2 & 0.27 & 1.63 & 52.6 \\
6 & \multirow{2}{*}{155} & 0.05 & 0.35 & 0.23 & 1.43 & 49.4 \\
7 & & 0.1 & 0.2 & 0.35 & 2.17 & 48.8 \\
8 & & 0.1 & 0.35 & 0.48 & 2.87 & 47.9 \\
\hline 9 & & 0.05 & 0.2 & 0.28 & 1.73 & 51.1 \\
10 & \multirow{2}{*}{180} & 0.05 & 0.35 & 0.36 & 2.07 & 50 \\
11 & & 0.1 & 0.2 & 0.3 & 1.9 & 50.7 \\
12 & & 0.1 & 0.35 & 0.3 & 1.93 & 50.4 \\
\hline
\end{tabular}

Figure 14 shows the display of the roughness meter during one measurement.

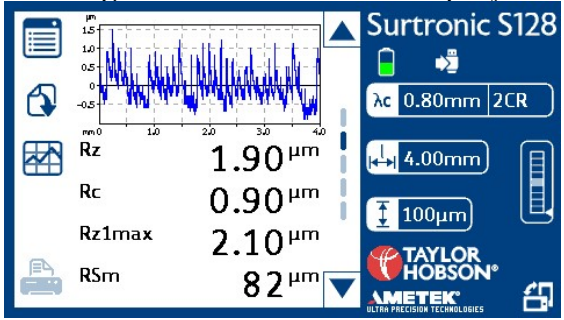

Figure14 Screen of the roughness meter after the measurement.

The best result in terms of surface quality is of samples 5 and 6 at cutting conditions that are proven to work on larger diameters of bearing rings.

3.3.2 Evaluation of the surface quality of the functional area by the non-contact method

The evaluation of the surface quality of the functional surface by the non-contact method was carried out on the Alicona instrument for samples 5 and 6, where the best results were obtained, and for sample 8, where the worst results were obtained. For relevance, sample 12 with the highest values of cutting conditions was also assessed. The results are shown in Table 7 .

Table 7 Values of selected surface quality parameters measured on Alicona. 


\begin{tabular}{cccccccc}
\hline $\begin{array}{c}\text { Sample } \\
\text { No. }\end{array}$ & $\begin{array}{c}\text { Ra } \\
(\mu \mathrm{m})\end{array}$ & $\begin{array}{c}\text { Rz } \\
(\mu \mathrm{m})\end{array}$ & $\begin{array}{c}\text { Rk } \\
(\boldsymbol{\mu m})\end{array}$ & $\begin{array}{c}\text { Rpk } \\
(\boldsymbol{\mu m})\end{array}$ & $\begin{array}{c}\text { Rvk } \\
(\boldsymbol{\mu m})\end{array}$ & $\begin{array}{c}\text { Rmr1 } \\
(\%)\end{array}$ & $\begin{array}{c}\text { Rmr2 } \\
(\%)\end{array}$ \\
\hline 5 & 0.273 & 1.459 & 0.883 & 0.217 & 0.255 & 11.77 & 91.83 \\
6 & 0.232 & 1.471 & 0.547 & 0.296 & 0.35 & 7.59 & 74.62 \\
8 & 0.328 & 1.644 & 1.068 & 0.191 & 0.175 & 10.65 & 94.85 \\
12 & 0.196 & 1.302 & 0.665 & 0.269 & 0.186 & 9 & 94.36 \\
\hline
\end{tabular}

Comparison of Ra and $\mathrm{Rz}$ values in the touch and non-contact method shows almost the same values for samples 5 and 6 , while better values were measured in samples 8 and 12 by the non-contact method. In the following Figures 15 to 22, detailed representations of the progression of the individual variables for the samples are given.
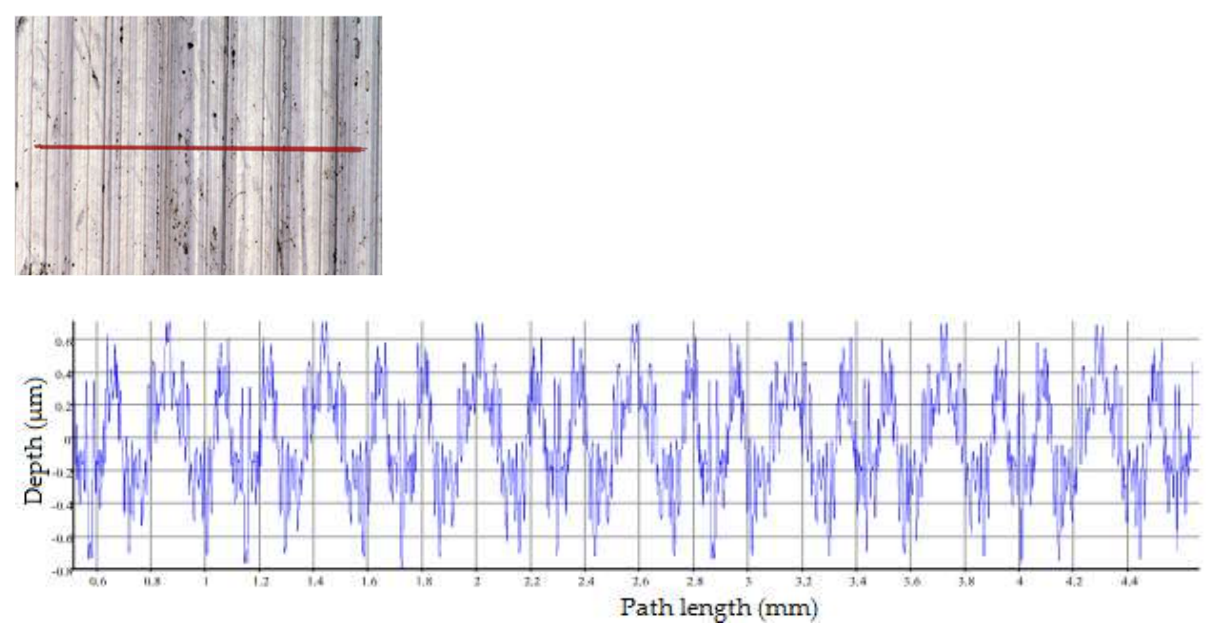

Figure 15 Profile measurement part 5: Ra $0.273 \mu \mathrm{m}$ Rz $1.459 \mu \mathrm{m}$.

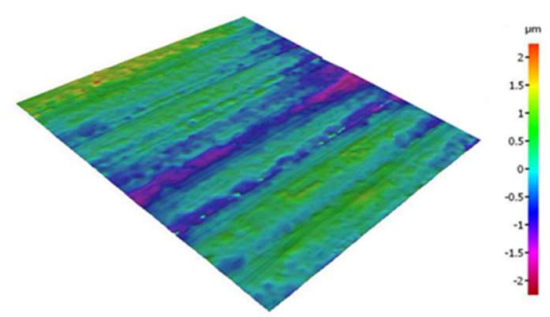

Figure 16 Spatial contrast profile display of the surface of part 5.

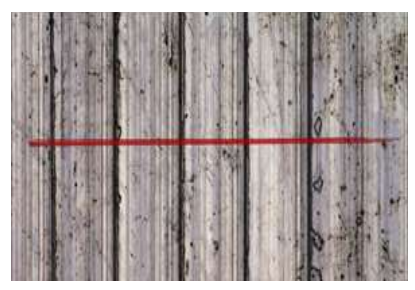




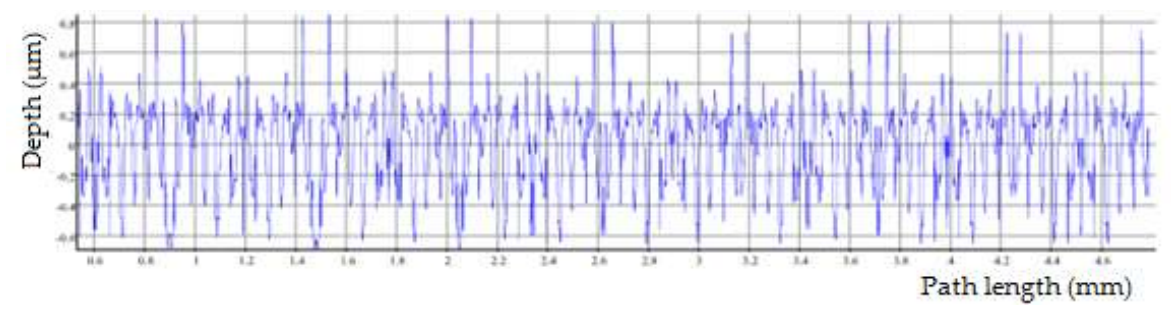

Figure 17 Profile measurement part 6: Ra $0.232 \mu \mathrm{m} \mathrm{Rz} 1.471 \mu \mathrm{m}$.

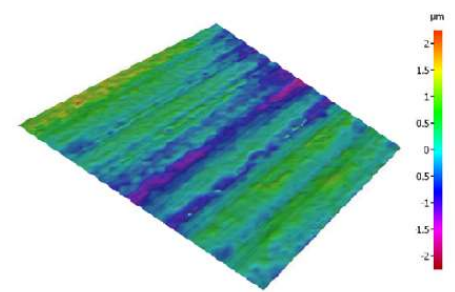

Figure 18 Spatial contrast profile display of the surface of part 6 .
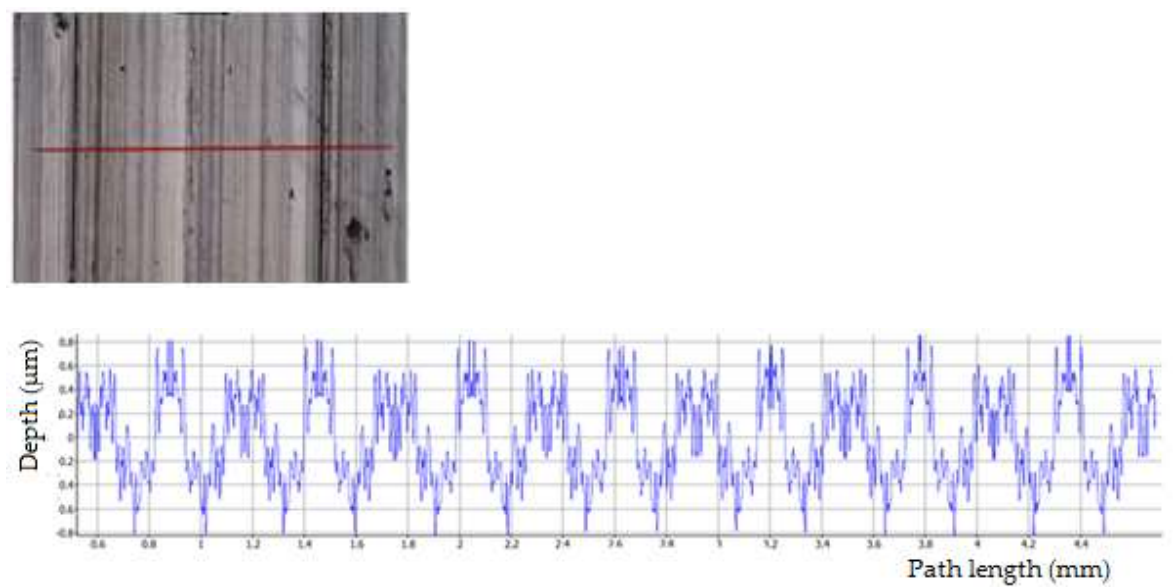

Figure 19 Profile measurement part 8: Ra $0.328 \mu \mathrm{m}, \mathrm{Rz} 1.644 \mu \mathrm{m}$.

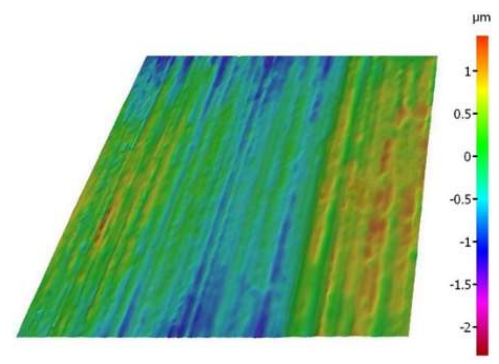

Figure 20 Spatial contrast profile display of the surface of part 8 .

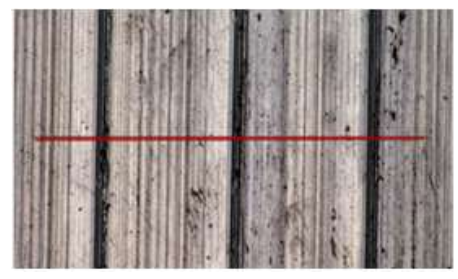




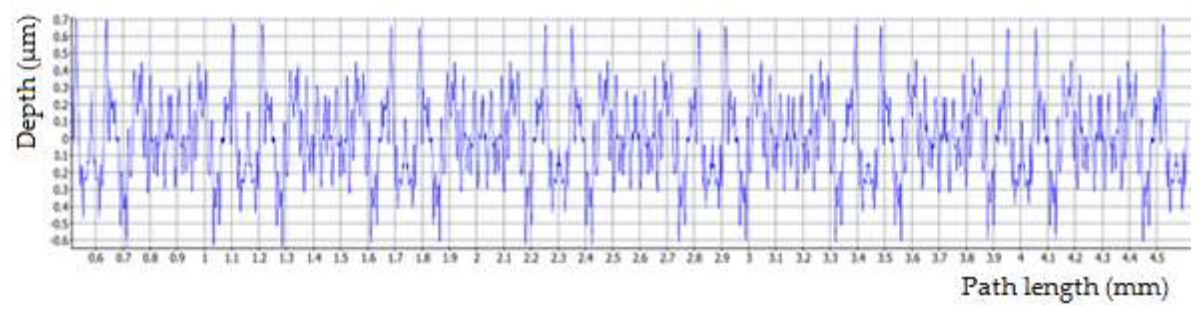

Figure 21 Profile measurement part 12: Ra $0.196 \mu \mathrm{m}, \mathrm{Rz} 1.302 \mu \mathrm{m}$.

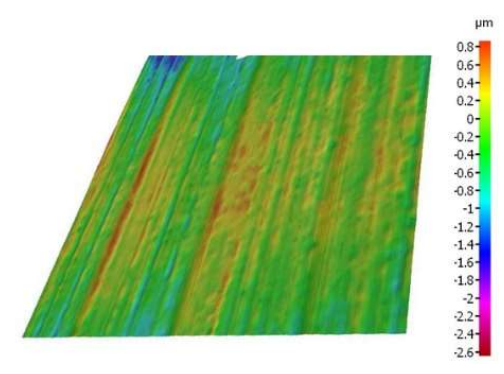

Figure 22 Spatial contrast profile display of the surface of part 12.

\section{Discussion}

The individual partial results of the experiment confirm the following facts:

- Using inserts from another manufacturer achieved similar surface quality results.

- $\quad$ The machined surface could be accepted for the 4 selected samples if $\mathrm{Ra}=0.3$ was considered as the cut-off value.

- Measurement of surface roughness values by both the touch and non-touch methods showed similar results.

- The construction of an empirical structural equation allows the prediction of the cutting force in finishing hard turning under similar machining conditions.

\section{Conclusions}

The article deals with two areas of assessing the results of hard turning of hardened materials. These are the evaluation of surface quality by the touch method, which is available in common industrial plants, and the verification of the measured values by the non-touch method, which in the case of laser-based measuring technology is more a matter of a scientific workplace. The second area focuses on the cutting force experiment, the result of which was used to develop a structural equation for the cutting force.

Author Contributions: Conceptualization, K.O.; methodology, J.C.; software, P.S and J.Z. All authors have read and agreed to the published version of the manuscript.

Funding: This research was funded by the project FV 40225, program TRIO, Ministry of Industry and Trade of the Czech Republic.

Institutional Review Board Statement: Not applicable.

Data Availability Statement: Not applicable.

Acknowledgments: Samples of semi-finished hardened material were provided by firm ZKL.

Conflicts of Interest: The funders had no role in the design of the study; in the collection, analyses, or interpretation of data; in the writing of the manuscript, or in the decision to publish the results. The authors declare no conflict of interest. 


\section{References}

1. Osička. K.; Kalivoda. M.; Chladil. J.; Mouralová. K.; Otoupalík. J. Machining of hardened bearing steels. Journal Proceedings in Manufacturing Systems. 2013. Volume 6. pp. 171-176.

2. Osička. K.; Fišerová. Z.; Otoupalík. J. Influence of cutting tool overhangs at machining of hardened steels. Manufacturing Technology. 2015. Volume 4. pp. 188-191.

3. Osička. K.; Fišerová. Z.; Otoupalík. J. Influence of cutting tool overhangs at machining of hardened steels. Manufacturing Technology. 2015. Volume 10. pp. 188-191.

4. Sedlák. J.; Tropp. P.; Chladil. J.; Osička. K.; Sliwková. P. High- speed cutting of bearing rings from material $100 C r 6$. Manufacturing Technology. 2015. Volume 10. pp. 899-908.

5. Sedlák. J.; Tropp. P.; Chladil. J.; Kouřil. K.; Polzer. A.; Osička. K. Analysis of selected aspects of turned bearing rings regarding required workpiece quality. Manufacturing Technology. 2016. Volume 11. pp. 612-622.

6. Osička. K.; Fišerová. Z.; Otoupalík. J.; Chladil. J. Tension of the surface layer in machining hardened steels. Manufacturing Technology. 2017. Volume 5. pp. 72-76.

7. Osička. K.; Chladil. J. Hardened steels and their machining. Crystals. 2021. 11. 182.

8. Neslušan. M. Sústruženie kalených ocelí (Turning of hardened steels). EDIS. 2009, pp. 253. ISBN 978-80-554-104-1.

9. Píška. M.; Metelková. J. On the comparison of contact and non-contact evaluations of a machined surface. MM Science Journal. 2014. Volume 7. pp.476-779.

10. Nwaogu. U C.; Tiedje. N.S.; Hansen. H. N. A non-contact 3D method to characterize the surface roughness of castings. Journal of Materials Processing Technology. 2013. Volume 213. pp. 59-68. 